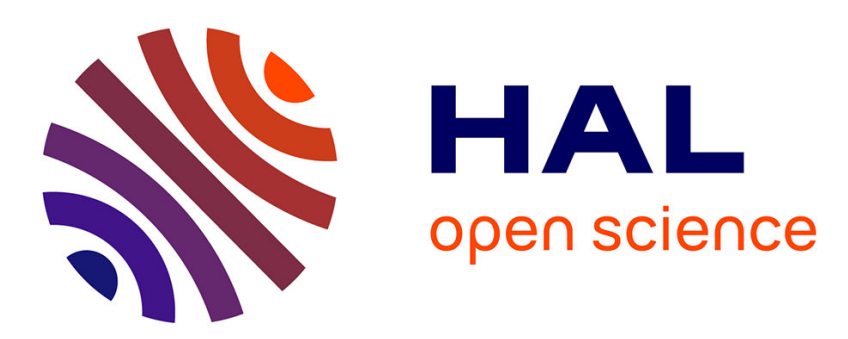

\title{
Surf's Up: Reducing Internet Abuse Without Demotivating Employees
}

Brian C. Gunia, Brice Corgnet, Hernán-González Roberto

\section{To cite this version:}

Brian C. Gunia, Brice Corgnet, Hernán-González Roberto. Surf's Up: Reducing Internet Abuse Without Demotivating Employees. Academy of Management Annual Meeting Proceedings, 2014, 2014 (1), 932-937 p. hal-02276674

\section{HAL Id: hal-02276674 \\ https://hal.science/hal-02276674}

Submitted on 3 Sep 2019

HAL is a multi-disciplinary open access archive for the deposit and dissemination of scientific research documents, whether they are published or not. The documents may come from teaching and research institutions in France or abroad, or from public or private research centers.
L'archive ouverte pluridisciplinaire HAL, est destinée au dépôt et à la diffusion de documents scientifiques de niveau recherche, publiés ou non, émanant des établissements d'enseignement et de recherche français ou étrangers, des laboratoires publics ou privés. 
Record: 1

Title: SURF'S UP: REDUCING INTERNET ABUSE WITHOUT DEMOTIVATING EMPLOYEES.

Authors: GUNIA, BRIAN C. ${ }^{1}$

CORGNET, BRICE 2

HERNAN-GONZALEZ, ROBERTO ${ }^{3}$

Source: Academy of Management Annual Meeting Proceedings. 2014, p932937. $6 p$.

Document Type: Article

Subject Terms: ${ }^{*}$ Computer crimes

*Internet access

*Employee crimes

*Work environment

*Internet use in business

Internet usage monitoring

Abstract: Cyberloafing represents a serious organizational problem. The current research compared the objective and subjective effects of the standard "top-down" solution with the effects of two "horizontal" solutions. This proceedings version presents a much-abbreviated version of the introduction, hypotheses, studies, and results. The full manuscript provides additional detail. [ABSTRACT FROM AUTHOR] Copyright of Academy of Management Annual Meeting Proceedings is the property of Academy of Management and its content may not be copied or emailed to multiple sites or posted to a listserv without the copyright holder's express written permission. However, users may print, download, or email articles for individual use. This abstract may be abridged. No warranty is given about the accuracy of the copy. Users should refer to the original published version of the material for the full abstract. (Copyright applies to all Abstracts.)

Author Affiliations: ${ }^{1}$ Johns Hopkins University, Baltimore, MD 21202

${ }^{2}$ Chapman University

${ }^{3}$ University of Granada

Full Text Word Count: 2909

ISSN: 2151-6561

DOI: $10.5465 / A M B P P .2014 .40$

Accession Number: 97634150

Database: Business Source Complete

\section{SURF'S UP: REDUCING INTERNET ABUSE WITHOUT DEMOTIVATING EMPLOYEES}

\section{INTRODUCTION}

Cyberloafing represents a serious organizational problem. The current research compared the objective and subjective effects of the standard "top-down" solution with the effects of two "horizontal" solutions. This proceedings version presents a much-abbreviated version of the introduction, hypotheses, studies, and results. The full manuscript provides additional detail.

Workplace internet access is a double-edged sword. The internet obviously makes it easier to exchange reports, access data, and purchase supplies, among many other activities (Reinsch, Turner, \& Tinsley, 2008). 
Yet, the internet also makes it easier to exchange tweets, access pornography, and purchase iTunes, among many other distractions. Since $60 \%$ of employees use workplace internet for personal reasons each day, costing U.S. corporations $\$ 85$ billion each year, cyberloafing represents a serious problem (Alder, Noel, \& Ambrose, 2006).

Organizations, aware of these issues, have taken strong measures to curb cyberloafing. As early as 2001, about two-thirds of organizations had implemented systems to monitor their employees' internet use (Alge, 2001), creating an internet monitoring industry later valued at more than $\$ 300$ million (Alder et al., 2006). Although different organizations use different monitoring systems, their systems tend to share a common characteristic: they are top-down, empowering senior employees to monitor the internet behavior of junior employees (Stanton, 2000a). The trend continues, although the efficacy of these systems remains unclear (Niehoff \& Moorman, 1993; Stanton \& Weiss, 2000), and their potentially problematic side-effects have been highlighted: top-down monitoring systems may demotivate employees (Alder et al., 2006; Ariss, 2002; Falk \& Kosfeld, 2006; Lepper \& Greene, 1975; Luhmann, 1979), ultimately exacerbating the very productivity problems they were intended to solve.

This issue inspired our interest in alternative approaches that might mitigate cyberloafing with fewer motivational consequences. To conceptualize those alternatives, we drew from research on self-determination theory (i.e., SDT; e.g., Gagne \& Deci, 2005) and control systems (Sewell, 1998). Briefly, SDT is a theory of motivation: it suggests that motivation ranges from controlled to autonomous, and people generally prefer situations that stimulate their autonomy (Deci \& Ryan, 1985, 2000; Ryan \& Deci, 2000). Research on control systems, in turn, suggests that organizations can control behavior through either vertical (top-down) or horizontal (peer-to-peer) systems, with both producing comparable compliance but vertical systems often demotivating the people being controlled (e.g., Enzle \& Anderson, 1993; Lepper \& Greene, 1975; Sewell, 1998; Welbourne, Balkin, \& Gomez-Mejia, 1995). We know of no research, however, that has empirically examined the motivational consequences of horizontal systems or compared them to vertical systems, in general or in the domain of cyberloafing.

Thus, we integrated models of SDT and control to document and compare the motivational and behavioral implications of vertical and horizontal solutions to cyberloafing. We theorized that horizontal systems may support autonomy better than vertical systems, while producing similar behavioral results. We thus predicted that--vis-à-vis the traditional, vertical approach to cyberloafing--horizontal approaches would generate fewer motivational consequences and a similar reduction in cyberloafing.

Our analysis focused on two horizontal systems: peer monitoring (the direct, horizontal analogue of top-down monitoring) and peer communication (the opportunity for peers to converse, and a more incidental form of control; Enzle \& Anderson, 1993). Our studies compared the effects of these two horizontal systems, the topdown approach, and the absence of a monitoring system (a baseline condition). Based on control systems research, we specifically predicted that any of the systems would generate comparable reductions in cyberloafing, relative to the baseline. Combining control systems research and SDT research, however, we predicted that people would be less demotivated by either horizontal system than the vertical system, and especially by peer communication, which stimulates relatedness.

Though inspired by an applied problem, this approach helps to integrate theories of motivation and control. Specifically, our approach may help to reveal whether horizontal systems limit the negative effect of control on motivation. It may also provide practical guidance to organizations trying to mitigate cyberloafing without demotivating their employees. Finally, it may provide what is, to our knowledge, the first controlled test on the efficacy of systems intended to reduce cyberloafing.

\section{CYBERLOAFING AND CONTROL SYSTEMS}

Cyberloafing (Henle \& Blanchard, 2008) occurs when an employee uses workplace internet during the working period for non-work purposes (Lim, 2002; Wagner, Barnes, Lim, \& Ferris, 2012). A variety of research has investigated the systems that organizations use to control behaviors like cyberloafing (e.g., 
cyberloafing; Alge, 2001; Carayon, 1993; Lepper \& Greene, 1975; Niehoff \& Moorman, 1993; Strickland, 1958). Among this literature's contributions is the insight that control systems can be categorized as vertical or horizontal (Piccoli \& Ives, 2003; Sewell, 1998; Welbourne et al., 1995). Under vertical control, an authority figure governs the behavior of employees (Sewell, 1998). Under horizontal control, groups of employees govern their own behavior (Welbourne et al., 1995: 883).

To prevent cyberloafing, organizations have largely relied on a particular form of vertical control: top-down monitoring. Top-down monitoring qualifies as vertical because it empowers an authority figure (e.g., an IT or HR leader) to watch and/or restrict the internet use of lowerlevel employees (Alder et al., 2006; Ariss, 2002; Spitzmuller \& Stanton, 2006; Stanton, 2000a; Wagner et al., 2012). The efficacy of top-down internet monitoring remains largely untested, however, so our first goal was to provide a controlled test.

Our second goal was to compare the behavioral effects of top-down monitoring and several forms of horizontal control. At the most basic level, horizontal systems differ from vertical systems in the identity of the people controlling: peers, rather than an authority figure, control (each other's) behavior (Sewell, 1998). As peers typically have no formal authority over one another, however, horizontal systems do not derive strength from authority, but rather from norms (Bettenhausen \& Murnighan, 1991). We investigated two horizontal control systems, both of which qualify as horizontal by making the normative expectations of peers salient. The first, peer monitoring, is the direct, horizontal analogue of top-down monitoring: peers watch one another, as opposed to a senior employee watching a junior employee. Thus, at its core, peer monitoring differs in the identity of the monitor(s). The second form of horizontal control, peer communication, is the opportunity to converse with peers. Thus, the core theoretical difference between the two horizontal systems is the ability to communicate versus monitor.

\section{HYPOTHESES}

Since both horizontal and vertical systems draw attention to other people's expectations (peers' or authority figures'), prompting individuals to weigh these considerations in their decision-making (Sewell, 1998), a diversity of findings (e.g., Malhotra \& Murnighan, 2002; Yamagishi, Cook, \& Watabe, 1998) has suggested that both vertical and horizontal control can reduce disfavored behavior relative to the absence of any system. For cyberloafing, we predict: Hypothesis 1: Relative to the baseline, top-down monitoring, peer monitoring, and peer

communication will lead to similar reductions in cyberloafing / increases in productivity. Since employees tend to see top-down monitoring as an overt attempt to control their behavior (Alder et al., 2006), however, it is likely to reduce their perceived autonomy, and thus their perceived motivation (Gagne \& Deci, 2005). Since peer monitoring places control of the monitoring in the hands of the monitored--and since other monitors have an equivalent level of authority--peer monitoring should better maintain perceived autonomy and motivation. Since peer communication does the same and also stimulates social interaction, which facilitates feelings of autonomy (Gagne \& Deci, 2005), it should have the fewest motivational costs. Thus:

Hypothesis 2: Relative to the baseline, top-down monitoring will reduce perceived autonomy the most, peer monitoring the next-most, and peer communication the least.

Hypothesis 3: Relative to the baseline, top-down monitoring will reduce perceived motivation the most, peer monitoring the next-most, and peer communication the least.

Finally, since perceived autonomy directly predicts perceived motivation (Gagne \& Deci, 2005):

Hypothesis 4: Perceived autonomy will mediate people's motivational reactions to the cyberloafing reduction systems.

Our research included two studies: an experiment (Study 1) and a survey (Study 2). The first study used a new, interactive, virtual environment in which interdependent individuals performed a mathematical task that also allowed them to check the internet, replicating many features of a real-world work environment. It tested 
the impact of the various systems on people's productivity and cyberloafing in an exhaustive and tightlycontrolled fashion. Study 2 turned to the motivational hypotheses, immersing a national sample in one of the systems and then recording their perceived motivation and autonomy.

\section{STUDY 1}

Participants were 240 undergraduates enrolled in a subject pool at a Western U.S. university; they earned an average of $\$ 26.30$ for a 2.25-hour experiment. The study included four conditions: baseline (no system), topdown monitoring, peer monitoring, and peer communication, with participants randomly assigned. The experiment was conducted using the Virtual Organizations software developed for the authors. In brief, the software allowed participants to choose between a laborious mathematical task and cyberloafing. Depending on condition, participants might also monitor or communicate with their other 9 team members--or be monitored by, and receive communications from them.

Hypothesis 1 predicted productivity improvement and internet reduction from each of the systems, relative to the baseline. In support, planned comparisons indicated that, relative to the baseline, top-down monitoring, peer monitoring, and peer communication all increased productivity. Unexpectedly, the increase was not significant for top-down monitoring. In line with Hypothesis 1, however, top-down monitoring led to productivity that did not differ from peer monitoring or peer communication. This generally supports the productivity component of Hypothesis 1 . Results also supported the cyberloafing component, as planned comparisons indicated that, relative to the baseline condition, top-down monitoring, peer monitoring, and peer communication all reduced cyberloafing. Compared to each other, however, the three systems produced comparable levels of cyberloafing

These results suggest that the traditional, top-down approach for mitigating cyberloafing is somewhat effective, as it decreases cyberloafing, though without a substantial boost in productivity. Yet, the results also suggest that horizontal systems oriented around peer monitoring and peer communication may perform the same function comparably well. Since managers in real organizations inevitably care about both the productivity benefits and motivation costs associated with any organizational intervention, Study 2 focused on employees' subjective motivational reactions to the internet control systems.

\section{STUDY 2}

Participants were 270 adults from across the U.S. who had agreed to participate in short online studies administered by Amazon MTurk for a small amount of compensation (here, \$.75). The design was the same as in Study 1. Participants read a scenario about a company with rampant cyberloafing, which had implemented one of the four systems. They then answered a series of questions including three manipulations checks, five questions about their perceived motivation (compiled into a motivation scale), 15 questions about their perceived autonomy (Baard, Deci, \& Ryan, 2000; compiled into an autonomy scale), and five questions about their expected cyberloafing (de Lara et al, 2006; compiled into an expected cyberloafing scale).

Hypothesis 1 predicted that any system would reduce cyberloafing relative to the baseline. In support, all of the systems reduced expected cyberloafing. Specifically, participants in the baseline condition scored highest on the expected cyberloafing scale: higher than the other three conditions combined and each of these conditions individually. Also as expected, participants in the top-down and peer monitoring conditions did not differ in expected cyberloafing. Unexpectedly, participants in the peer communication condition scored higher in expected cyberloafing than those in either monitoring condition (though lower than those in the baseline condition). Nevertheless, these data supported the effectiveness of both the vertical and horizontal systems relative to the baseline.

The main purpose of this study was to test the motivational hypotheses (2-4). Hypothesis 2 predicted a distinct pattern of perceived autonomy. The data were supportive: participants in the top-down monitoring condition scored lowest on the perceived autonomy scale, followed by peer monitoring, peer communication, and the baseline. All of these differences were significant except for the difference between peer 
communication and the baseline. This generally supports Hypothesis 2, suggesting that peer communication may have been even more autonomysupportive than expected. Hypothesis 3 predicted that perceived motivation would follow the same pattern. It did, as participants in the top-down monitoring condition scored lowest on the perceived motivation scale: lower than the other three conditions combined and each individually. Additionally, participants in the peer monitoring condition scored lower on the perceived motivation scale than those in the baseline and peer communication conditions, but higher than those subject to top-down monitoring. Finally, participants in the peer communication condition scored higher than those in the top-down monitoring or peer monitoring conditions. This generally supports Hypothesis 3 , suggesting that the horizontal systems, especially peer communication, dampen motivation less than the top-down system. Hypothesis 4 predicted that autonomy would mediate people's motivational reactions to the systems. A series of regressions and bootstrap tests (Preacher \& Hayes, 2004) showed that it did.

\section{This study replicated the results of Study 1 regarding the effectiveness of all systems at} reducing cyberloafing, and it provided a test of the motivational hypotheses. In support of the latter hypotheses, top-down monitoring reduced perceived autonomy more than peer monitoring, which reduced perceived autonomy more than peer communication (Hypothesis 2); peer communication appeared to impose few consequences for autonomy. Perceived motivation generally followed the same pattern (Hypothesis 3 ), and the effect of the systems on perceived motivation was mediated by perceived autonomy (Hypothesis 4). Thus, the findings consistently supported all four hypotheses, with a very different sample and method than Study 1 's.

\section{GENERAL DISCUSSION}

Organizations now see cyberloafing as a major threat to their productivity. A productive organization, however, is an organization of motivated employees. The current research suggested that the most common approach for reducing cyberloafing, top-down monitoring, may demotivate employees, winning the internet "battle" but potentially losing the motivational "war." This paradox piqued our interest in systems that could reduce cyberloafing with fewer motivational consequences. Theories of control and motivation drew our attention to horizontal forms of control, of which we studied two: peer monitoring and peer communication. As a particularly conservative test, we used especially subtle manipulations. The effects were nevertheless pronounced: Compared to the vertical, top-down system, these horizontal systems appeared to mitigate cyberloafing while better maintaining motivation. These results suggested that horizontal systems may offer better solutions to cyberloafing, mitigating cyberloafing while maintaining motivation, with important theoretical and organizational implications.

\section{Theoretical Implications and Organizational Implications}

Interdependence has become a mainstay of modern organizations (Reason, 2000). In addition, many organizations have asked at least some of their interdependent employees to assume "the responsibility for rationalizing and intensifying their own work activities" (Sewell, 1998: 401). Without replacing the vertical mechanisms that have long governed organizational behavior, then, horizontal mechanisms are at least beginning to complement these mechanisms. Drawing from theories of control and motivation, our paper offered what we think is among the first empirical comparisons of the two systems' effects. In terms of objective outcomes, the vertical and horizontal systems generally substituted, as they were comparably effective in reducing cyberloafing. In terms of subjective preferences, however, the vertical and horizontal systems were not interchangeable, as people decidedly preferred the latter. To research on control, then, our findings add a potential disconnect between objective and subjective reactions. Though long studied in the domain of vertical control (e.g., Lepper \& Greene, 1975), subjective reactions to horizontal control have received less attention. At a minimum, then, it seems important for future research on vertical and horizontal control to consider objective and subjective factors in tandem, noting when the system that works is and is not the system that motivates the people being controlled. This is perhaps the central theoretical implication of our research, which also holds important implications for theories of motivation and cyber-loafing. 
